\title{
Memory in Early Modern Europe, 1500-1800
}

Review Number: 2221

Publish date: Thursday, 8 February, 2018

Author: Judith Pollmann

ISBN: 9780198797555

Date of Publication: 2017

Price: $£ 30.00$

Pages: 256pp.

Publisher: Oxford University Press

Publisher url: https://global.oup.com/academic/product/memory-in-early-modern-europe-1500-18009780198797555?cc=gb\&lang=en \&

Place of Publication: Oxford

Reviewer: Sarah Ward Clavier

The aim to cover, in a single monograph, patterns and trends in memory across early modern Europe is an ambitious one. Yet if anyone could achieve this it would be Judith Pollmann. This is an ambitious book in its chronological and geographical scope, but is also pioneering in providing a meta-narrative of continuity and change in early modern memory practices. Pollmann attempts to demonstrate wider trends in memory practices, show what we do and do not know about early modern memory, and to begin a conversation between scholars working on memory before and after 1800. She makes a virtue of her work being a survey of a very wide field, using the work of scholars focusing on different periods and countries, as well as her own extensive research on memory in the Low Countries. Her principal arguments focus on the reasons for change in memory practices, and provide a new way of conceptualising the history of memory. Pollmann argues that the authority of the past changed, and ultimately led to the belief that there could be moral, religious, and social progress, as well as economic and material improvements. This notion of progress diminished the role and value of tradition and custom. Secondly, however, Pollmann contends that new ideas about the past did not obliterate the older ones: "The history of memory is not to be imagined as a series of paradigm shifts, forged through critical junctures, memory crises, and cultural revolutions, but is actually much more cumulative' (p. 197).

Pollmann begins by examining personal memory, life-writing, and the reasons why it was produced. She explores why personal memory mattered to early modern people, and what they thought was memorable about themselves. Family memory was crucial for several reasons. It was vital to demonstrate legitimacy in a world where this was important in terms of legal and social status. It was also part of the religious culture of the age, as prayers for the soul after death relied to a large degree on family memorialisation of the decreased. Pollmann assesses several key debates in the field of life-writing and early modernity. First, she raises the question of the creation of the individual, and the assumption that early modern people had a collective rather than individualistic sense of the self. She effectively dismisses this canard by explaining the exemplary purpose of early modern life-writing. Rather than demonstrating a lack of inner individualism, pre-modern memoirs simply served a different purpose to their modern counterparts. Whereas modern memoirs from Rousseau onwards often tended to focus the development of a unique self in an emotional and moral sense, early modern life-writing was generally written to demonstrate the consequences of human 
behaviour and the ways that divine providence intervened in people's lives. So while in both periods a life could be viewed as a journey, for modern memoirs this was a journey to self-realisation, whereas in early modern autobiographical writings it was an archetype of a pilgrimage. Pollmann posits the idea of social and cultural 'scripts', in which the goal was the opposite of originality - it was to meet expectations and to provide others with experiences to learn from.

Second, she highlights the importance of bodies within early modern life-writing. The focus on externalities has frustrated many a scholar seeking personal insights and emotional content in pre-modern autobiographies. Yet it, too, had a purpose. The prevailing theory of the humours, and the resulting link between mental and physical symptoms, made it logical to discuss physical externalities within memoirs. As Pollman argues, 'In a culture that thought of emotional change as a physical process, the decision to structure memories around the state of one's body was an obvious choice' (p. 29). This is perhaps the least successful section in the chapter. It is both too brief to be satisfying, and long enough to disrupt the flow of explanation. As a point in the larger narrative about the exemplary purpose and reasoning behind the form of autobiographical writing in the period it clearly merits inclusion. In this particular book, it may have rendered the chapter more persuasive and coherent had it formed a paragraph rather than an entire subsection, leaving a fuller exploration for a discrete article.

Chapter two is a fascinating discussion of the debate about the rise and impact of 'historical consciousness'. Pollmann dissects and questions arguments about the replacement of synchronic or analogical conceptions of history with an awareness of the difference between past and present, and change over time. Rather than envisaging a linear process of the development of historical consciousness, Pollmann persuasively argues that early modern Europeans deliberately used anachronism as a rhetorical lens through which to analyse the present. They were aware of the difference between past and present and, indeed, were well able to portray and scrutinise these changes. The two forms of history, therefore, existed in tandem, and had different purposes. As a correction to the conventional narrative offered by Keith Thomas, Eric Hobsbawm, Peter Burke and their heirs, this makes a good deal of sense. Such awareness is evident in the early modern Welshman's use of fictive Biblical pedigrees as a rhetorical tool to demonstrate authority and status, as it was in the examples offered by Pollmann of 17 th-century Dutch printers.

In chapter three Pollmann moves on to consider the role of custom in early modern Europe. She explores how custom could either be used to challenge or confirm authority, using examples from England, the Low Countries, and Germany. She quite rightly highlights the use of custom by individuals or groups of humble stock, although this is declared with a degree of excitement that would be surprising to many social historians who have worked with issues such as property or boundary disputes. Pollmann also examines how and why the status of custom changed over the period 1500 to 1800 . The role of codification was particularly important. As Pollmann convincingly argues, codifying custom robbed it of its essential flexibility, and over time made it less authoritative. Her description of the process of the delegitimising of custom is compelling, and the negative impact of intellectual movements like humanism and antiquarianism, as well as ideas of cultural hierarchy, is revealed. The drawing together of such diverse and complex strands of intellectual, religious, and social history is one of the greatest achievements of the book, and its particularly showcased in this chapter.

Chapter four discusses the role of memory in 'imagined communities'. Pollmann disputes the claims of modernist historians that national memory cultures only emerged from c.1800 onwards. Recent discoveries concerning the interplay of scribal, oral, and printed material, and the resulting spread of news and ideas, have done a lot to dispel the impression that only literate elites could even conceive of a national culture. Here Pollmann examines interactions between vibrant local memories and national or proto-national memory cultures. Some of these local memory cultures revolved around religion, such as the 'Sacrament of Miracle' in Brussels, and Poitiers' 'Miracle of the Keys'. They were used to convey the prestige of cities, to emphasise the strength of its religious devotion, or (as with Poitiers) to position the city within a larger world of dynasty or nation without losing its own identity. Secular traditions also existed, particularly in urban areas. Oaths, processions, commemorations and feasts all formed part of urban community memory 
practices. Pollmann uses an example from the Low Countries to demonstrate how local memory cultures could become national. She traces how commemorations of suffering in the siege of Leiden became focused on communal victimhood, as a way to heal local divisions following the siege. This victimhood became part of a wider theme in the public memory culture of the Dutch Republic, and memories of Spanish cruelty were used to bring unity in the face of attempts to seek peace with Spain. Pollmann argues that, rather than thinking of local and national memory cultures as being part of a linear progression, they were actually 'interrelated modes of thinking about the collective past' (p. 117). Transnational memories could bolster local memory cultures and local memories could serve national purposes.

In chapter five Pollmann proceeds to consider myth and legend, their coexistence with 'history', and their relationship with early modern memory practices. While earlier generations of scholars saw myth and history as mutually exclusive, modern historians and social scientists acknowledge their coexistence. Furthermore, they now realise the role of myth in social memory. Pollmann describes, using compelling examples such as the Dordrecht story of the baby, the cat, and the cradle, what was necessary for a myth to survive and be believed. It had to be framed historically, or be supported by material evidence (ideally both). It had to be set in a time or a place, have spatial 'markers', and a witness. Early modern myth also helped to perpetuate historical memories, when the use of mythical elements provided a satisfying narrative, ensuring that a historical claim endured. Thus, myth and history supported each other, and memory practices aided in the transmission of evidence for both. Thus oral tradition, printed stories, and objects together created 'a tale that benefits both from a transcendent message and from a semblance of historical plausibility' (p. 133). Fascinatingly, Pollmann reveals the role of scholars in perpetuating and amplifying myths: whether trying to prove a myth was historically rooted or attempting to dispel a story, the attention of antiquarians and academics such as the Pied Piper of Hamelin only made the stories more widespread.

Deliberate forgetting, or the attempts to impose acts of oblivion, is the subject of chapter six. In it Pollmann explores the purposes of such acts, and asks whether they could ever function as a successful strategy for peacekeeping. Examining the French Wars of Religion, the Dutch Revolt, and the English Civil Wars, she discusses oblivion clauses and the reasons behind them. She proposes that acts of oblivion remained popular because memory was so potent. Public memorialisation had to be managed so that future contention could be avoided. Her chosen case studies demonstrated that such oblivion clauses did not stop disputed events being commemorated, and that people found ways around the oblivion clauses. Citing Ross Poole's work, Pollmann argues that this is missing the point of such acts of oblivion. They were there to prevent action in the present, rather than to ask people to deny knowledge of the past. Such acts, 'say that past events are not acknowledged as a legitimate reason for action in the present; they are of the past' (p. 151). This enabled societies to re-establish the continuity that was so valued in early modern times. In a world where custom, tradition, and the past were so important, this was a reasonable strategy. As Pollmann convincingly avers, it also explains why they fell out of use - the European world changed, and custom fell out of favour. Acts of oblivion did not make sense when change, modernity, novelty and progress were prized above tradition.

Pollmann's final chapter concerns the ways that early modern European people remembered violence, in local, national, and 'cosmopolitan' senses. It is understandably difficult to discover evidence of early modern individuals' emotional reactions to atrocities that they have suffered. As argued in chapter one, these events had little exemplary role to offer, in a personal sense. Suffering physical violence, sexual assault, or the destruction of property was shameful. Events were recorded and described, but without the emotional content that is much more often present in modern times. Descriptions of material losses could serve as a form of commemoration, but otherwise surviving evidence of personal reflections on suffering is scarce. Pollmann posits the argument that this was because early modern people tended to, wherever possible, reframe the memories as meaningful or positive. Providentialism was crucial in this - God's grace was responsible for interventions in human affairs, whether survival in war, or plague. He punished those who were sinful, and saved those who were not. Finally, Pollmann introduces Daniel Levy and Nathaniel Sznaider's term 'cosmopolitan memory' as a way to interpret the interaction between local experiences and global concerns. She discusses confessional cosmopolitan memories, from the execution of Mary Queen of Scots to the St Bartholomew's Day massacre of 1572. Both of these events were commemorated in countries 
across Europe, and some others, such as the work of the Spanish and Portuguese Inquisition, continued in the 18th century to become memories of injustice and the fight against free speech and thought.

In many ways, Memory in Early Modern Europe is a remarkable achievement. Pollmann refutes a number of fairly entrenched historiographical views, and in doing so carves out a thesis of continuity as well as change, concurrent concepts of the past rather than a linear narrative leading from myth to history. She engages successfully with the scholarship of political theorist and modern historians as well as with her early modernist peers, and synthesises a wide range of evidence, both chronologically and geographically. The principal weaknesses of the book are twofold. Firstly, the nature of the aim to provide an overview inherently leads to uneven coverage of both the period and Europe. After all, Pollmann can only synthesise using existing scholarship and her own research. She admits this in her introduction, and I would argue that this inherent weakness is excused by the overall achievement of the book. Secondly, the structure of the book occasionally feels arbitrary. Chapters do not always flow naturally from one theme to another (except in chapters six and seven, both covering the theme of violence), and sometimes feel like self-contained thematic essays rather than material that is building naturally to an over-arching conclusion. This is ameliorated to some extent in the conclusion, which draws together many of the rich strands of argument in a more integrated way.

Altogether, however, this is an excellent book and a fine achievement. It will be useful both for those approaching the history of early modern memory for the first time, or for those who wish to place their own research into a wider context. Its arguments will be the subject of debate, but I have no doubt that this was partly the intention of the author. If it does so, this book will begin the historiographical conversation that it aimed for.

The author has sent the following response: 'I am grateful to Sarah Ward for her very well-considered and constructive review of my Memory in early modern Europe. I am glad she found much to her liking in the book. I also note her points of criticism, but do not think they require an extensive response.'

Source URL:https://reviews.history.ac.uk/review/2221

\section{Links}

[1] https://reviews.history.ac.uk/item/278411 